\title{
PARÁBOLA MODERNA Y PENSAMIENTO UTÓPICO EN F.J. HINKELAMMERT
}

\author{
JOSÉ SERAFÍN BÉJAR BACAS \\ Facultad de Teología de Granada
}

\begin{abstract}
RESUMEN: La actual situación socio-económica está poniendo de manifiesto la crisis del estado del bienestar. Se corre el riesgo de dar por sentado que el neoliberalismo, con la correspondiente totalización del mercado, es la única alternativa posible. Así, llegamos a la difuminación de todo pensamiento utópico, tachado de irreal, y a la sacralización de un pensamiento que se presenta a sí mismo como el único discurso realista. En este contexto, podemos comprender también la degradación de la política que, dentro del marco dado, se presenta como mero arte de lo posible. Para realizar una valoración crítica de la situación, proponemos un recorrido por el pensamiento de F.J. Hinkelammert, atendiendo a su análisis de la razón utópica y a su crítica al neoliberalismo como utopía o ideología encubridora del actual status quo.
\end{abstract}

PALABRAS CLAVE: modernidad, utopía, postmodernidad, nihilismo, neoliberalismo.

\section{Modern Parable and Utopian Thinking by F. J. Hinkelammert}

ABSTRACT: The present socioeconomic situation is making manifest the crisis of the welfare state. We are running the risk of accepting that neo-liberalism, with the corresponding totalization of the market, is the only possible alternative. Thus, we reach to the fading away of all Utopian thought, accused of unreal, and to giving official approval to a thought that offers itself as the only realistic discourse. In this context, we can also understand the degradation of the politics that, within the given frame, offers itself as mere art of the possible. In order to carry out a critical assessment of the situation, we propose an itinerary through the thought of F. J. Hinkelammert, paying attention to his analysis of the Utopian reason, and to his criticism of neo-liberalism as Utopia or ideology, which hides the actual status quo.

KEY WORDS: modernity, utopia, postmodernity, nihilism, neo-liberalism.

\section{Definición De PaRÁbola y PRESENTACión DEL AUTOR}

Entendemos por parábola del tiempo moderno una evocación de la historia que recorre la exaltación y crisis de una razón emancipada que, en el discurso programático de I. Kant Was ist Aufklärung?, alcanza su carta de ciudadanía. De ahí que la polisemia del término "parábola» nos ayude a ilustrar la verdad de la realidad que pretendemos describir. En efecto, una parábola es una figura geométrica matemática que describe una curva en ascenso hacia una cumbre que, al ser alcanzada, decae de nuevo. En este sentido, la modernidad es entendida como un proceso de ascenso y bajada que tiene como momentos claves la emancipación de la racionalidad crítica, su crisis y el desenvolvimiento de la misma. Pero también, la parábola es una forma literaria consistente en un relato figurado que, por analogía o semejanza, deriva una enseñanza relativa a un tema que no le es explícito. Desde este segundo significado, la modernidad va a ser descrita como un progresivo avance en la mitologización de una racionalidad adulta que, pretendiendo desligarse de lo mitológico, modela nuevas figuraciones míticas.

Queremos realizar esta reflexión en el conjunto del pensamiento de F.J. Hinkelammert. Así, la evocación de la aventura moderna se establece como el principio formal desde el cual se quiere leer la entera obra del pensador alemán, afincado en Costa Rica. Y esto por dos razones: primero, la búsqueda de un principio formal a la hora de 
realizar una investigación se presenta como pertinente si queremos ir más allá de una mera compilación de ideas para llegar a una verdadera síntesis con impronta personal, pero que no traicione al autor; segundo, tomamos la reconstrucción de la parábola de la modernidad como hipótesis de partida, con la intuición de que la misma, establecida como marco óptico de lectura de la obra de F. Hinkelammert, es capaz de constituirse en criterio de reorganización y sistematización de la entera literatura del filósofo alemán.

Así pues, pretendemos que este doble vector sirva al esclarecimiento de un pensamiento que puede tener una fuerte carga profética de cara a la humanización del mundo que nos ha tocado vivir; especialmente, en el momento económico, social y político en que nos encontramos. Con todo, se trata de un primer acceso que no descarta nuevos desarrollos de alguno de los puntos que ofrecemos aquí en consideración. Por tanto, es importante hacer notar desde el principio, no la minuciosidad del análisis de las obras de Hinkelammert, sino el esbozo de un esquema de comprensión crítico que facilite ulteriores acercamientos a su trabajo.

Procedemos ahora, como parte de este primer punto, a una breve presentación del autor objeto de estudio ${ }^{1}$. Franz J. Hinkelammert es, sin duda, y aunque poco conocido aún en nuestro país, uno de los investigadores sociales más importantes de América Latina. Nacido en Alemania en 1931, llega a la adolescencia bajo el régimen nazi, lo que le permite un primer acercamiento, aunque parezca paradójico, a posturas radicalmente anti-utópicas. De hecho, es sorpresivo a nuestro autor el visceral anticomunismo del nazismo, junto a la negación de toda utopía y universalidad ética. De ahí que, ligado al sustrato mismo de su personalidad, se encuentre una reflexión sobre los procesos autodestructivos de la modernidad o «ideologías de la muerte».

Hinkelammert estudia economía, filosofía y teología en las universidades de Freiburg, Hamburg, Münster, y en la Universidad Libre de Berlín, en la cual es profesor asistente entre 1959 y 1963 . Allí se doctora en economía en 1960 con una tesis sobre El desarrollo económico de la Unión Soviética.

En su período de formación universitaria recibe la influencia del racionalismo crítico y constata el predominio de la figura de K. Popper. Así, se acerca a un estudio profundo de su pensamiento, especialmente mediante la lectura atenta de La sociedad abierta y sus enemigos. De esta manera, nuestro autor reconoce que se siente críticamente interpelado por Popper y no llega a percibir la relación entre tal pensamiento y distintas formas de apología de la anti-utopía. De este periodo, sin duda, viene el interés por la obra de este filósofo, la cual ha analizado críticamente en su dimensión epistemológica en Ideologías del desarrollo y dialéctica de la historia, de 1970, y en su filosofía política y económica en diversas obras, especialmente en Crítica de la razón utópica, de 1984.

Después de dicha experiencia docente, comienza a residir en Chile desde 1963 y, a causa de la irrupción de la dictadura militar, tiene que salir del país en 1973. Durante su estancia en Chile realiza una extraordinaria labor como investigador y profesor en Ilades y en el Centro de Estudios de la Realidad Nacional, Ceren, de la Universidad

1 Para esta breve reseña biográfica cfr., principalmente, J. Vergara Estévez, Franz. Hinkelammert, El nihilismo al desnudo. Los tiempos de la globalización, en www.revistapolis.es; la entrevista realizada a nuestro autor por Fernando Arellano Ortiz el 15 de febrero de 2007 en www.socialdemocracia.org; la entrevista de Henry Mora, director del Departamento de Economía de la Universidad Nacional (UNA) de la ciudad de Heredia (Costa Rica), realizada en enero de 2000 y recogida en Hinkelammert, F. J., El nihilismo al desnudo. Los tiempos de la globalización, Santiago de Chile 2001, 255-297; y Cfr. Pérez TAPIAS, J. A., El pensamiento radical de Franz. Hinkelammert: convocatoria para la solidaridad ante la globalización capitalista, en F.J. Hinkelammert, Solidaridad o suicidio colectivo, Granada 2005, 7-24. 
Católica. En esta etapa, publica cuatro libros: Economía y revolución, en 1967, junto con Ideologías del desarrollo y dialéctica de la historia, El subdesarrollo latinoamericano, y Dialéctica del desarrollo desigual, todos ellos en 1970. En estos años madura su pensamiento en el análisis de las obras de Marx, Bloch, Marcuse, Hayek, Popper, y otros autores. Asimismo, participa intensamente en la discusión teórica sobre la teoría de la dependencia, a la cual hizo aportes relevantes, expuestos en las obras mencionadas, de una parte, y de otra, en el debate sobre el socialismo. También, su experiencia intelectual y política en Chile le plantea importantes interrogantes sobre lo sustantivo de la obra de Marx, respecto al papel del cristianismo conservador en la legitimación de las formas de dominación, sobre la construcción del discurso de racionalización de la represión, el significado del desarrollo, sobre el sentido y función de las utopías políticas..., y otros temas, los cuales ha desarrollado en obras posteriores.

A su salida de Chile, regresa a Alemania, y desde 1973 a 1976, es profesor invitado en la Universidad Libre de Berlín. En esa allí donde, en 1976, publica su reflexión sobre La radicalización de derecha de los demócrata-cristianos. Después de este breve periodo de tiempo, regresa a América Latina, primero como director de Postgrado en Política Económica de la Universidad Autónoma de Honduras, después como profesor e investigador de Consejo Superior Universitario de Centro América y, por último, se instala en San José de Costa Rica. En esta ciudad, con un grupo de teólogos y científicos sociales latinoamericanos, entre los cuales se encuentra Hugo Assman, Pablo Richards, Elsa Tamez, y otros, crea el Departamento Ecuménico de Investigaciones (DEI). Este centro de investigaciones es quizá el más importante de teología de la liberación y uno de los principales de pensamiento crítico de toda América Latina. Desde entonces ha publicado un conjunto de investigaciones entre las que se cuentan Las armas ideológicas de la muerte e Ideología del sometimiento, ambas de 1977; Crítica de la razón utópica, en 1984; Democracia y totalitarismo, en 1987; La deuda externa de América Latina, en 1988; La fe de Abraham y el Edipo occidental, en 1989; Sacrificios humanos y sociedad occidental: Lucifer y la bestia, de 1991; Cultura de la esperanza y sociedad sin exclusión, en 1995; El mapa del emperador, de 1996; El grito del sujeto, en 1998; El huracán de la globalización, de 1999; El nihilismo al desnudo. Los tiempos de la globalización, de 2001; El sujeto y la ley, de 2003; Hacia una crítica de la razón mítica. El laberinto de la modernidad, del año 2007; y un sin fin de artículos en revistas especializadas.

No obstante la riqueza de sus investigaciones, mostramos especial interés en la presente reflexión por todo aquello que hace referencia al análisis de las utopías modernas; principalmente sus análisis del actual capitalismo neoliberal y la búsqueda de soluciones a la totalización impuesta por un mercado que genera cultura nihilista. Esta será la tesis que especialmente nos ocupe en la presente reflexión, por su pertinencia para comprender la actual crisis de modelo socio-político-económico en que nos encontramos. Afirma Pérez Tapias:

Hinkelammert se apresta desde tiempo atrás a la reconstrucción de alternativas, y ello pone en juego esa crítica que llega histórico-materialistamente al fondo de lo que se gesta en la dinámica económica, para desde ahí señalar una cuestión fundamental: la necesidad de que la razón utópica se someta a crítica, para salir de sus desastrosos desvaríos. Es decir, hace falta una crítica de la razón utópica, entendida como autocrítica de la misma razón en tanto que utópica, atendiendo a las condiciones de posibilidad de su propio ejercicio ${ }^{2}$.

\footnotetext{
2 Pérez TAPIAS, J. A., El pensamiento 12.
} 
Después de esta presentación, articulamos la exposición de su pensamiento, en lo referente a la parábola de la modernidad, en tres momentos consecutivos: primero, la modernidad o la utopía como meta escatológica secularizada; segundo, la postmodernidad o la anti-utopía como justificación del status quo; tercero, lo útil frente al cálculo de utilidad o yo soy el otro. Vayamos por partes.

\section{LA MODERNIDAD O LA UTOPÍA COMO META ESCATOLÓGICA SECULARIZADA}

El peso de la tradición cristiana a la hora de comprender el proceso emancipatorio de la modernidad es un hecho obvio para Hinkelammert. Podríamos conectar aquí con la conocida reflexión de K. Löwith al respecto: «los modernos elaboran una filosofía de la Historia secularizando los principios teológicos y aplicándolos a un número siempre creciente de hechos empíricos» ${ }^{3}$. En este sentido, es interesante constatar cómo el pensamiento histórico, en referencia a otras culturas y religiones de la humanidad, tiene su referente ineludible en el continente europeo. Y ahí ubicados, puede surgir una confusión: creer que dicho pensamiento histórico se remonta al legado clásico y al cristianismo. Sin embargo, si queremos comprender bien la moderna filosofía de la historia y su tensión escatológica secularizada, hay que referirla a un insoslayable origen cristiano. Así pues, el historiador clásico siempre preguntó: "¿cómo llegó a ocurrir tal cosa?»; mientras el moderno exclama: «¿hacia dónde vamos?». Así, el universal significado histórico de esta orientación escatológica reside en haber logrado vencer el ancestral miedo al destino y al ciego azar. Por tanto, y en palabras de Löwith:

El futuro es el verdadero horizonte de la historia, suponiendo siempre que la verdad se basa en la fe judeocristiana de una salvación. Y como occidente es a pesar de todo un occidente cristiano, su autoconciencia histórica también es escatológica: de Isaías hasta Marx, de san Agustín hasta Hegel, de Joaquín de Fiore hasta Schelling. Esto también es válido para la práctica revolucionaria. No se habrían producido las revoluciones inglesa, francesa ni rusa sin la fe en el progreso, y no habría una fe mundana en el progreso sin la fe originaria en un objetivo trascendental de la vida ${ }^{4}$.

Situado en esta clave, para Hinkelammert, bajo la apariencia de secularización, lo que se produce es una transmutación del elemento religioso trascendente desde la categoría clave "reino de Dios» ${ }^{5}$ a las más variadas proyecciones ideológicas tanto burguesas como revolucionarias ${ }^{6}$. O de otra manera, «el deseo revolucionario de realizar el

3 Löwith, K., El sentido de la historia. Implicaciones teológicas de la filosofía de la historia, Madrid 1956, 35. También afirma en la página 282: «Desde que nos preocupa la Historia y el historicismo, estamos inclinados a creer que la moderna conciencia histórica se origina con el pensamiento hebreo y cristiano, esto es, con la consideración escatológica hacia una consumación futura».

4 Löwith, K., El hombre en el centro de la historia. Balance filosófico del siglo XX, Barcelona 1998, 138s. Afirma Hinkelammert en Sacrificios humanos y sociedad occidental: Lucifer y la bestia, San José 1998, 182: «Desde la aparición del cristianismo, todo pensamiento utópico se vincula con la imaginación de la Nueva Tierra, tal como ella está presente en todo el mensaje cristiano y expresada en los últimos capítulos del Apocalipsis».

5 La transmutación del reino de Dios al orden de la inmanencia, recibirá de nuestro autor el nombre genérico de «sociedad perfecta» y ésta se irá reconfigurando, desde los diferentes horizontes utópicos, en la iglesia de la cristiandad, el mercado liberal, la cultura de la guerra en el nazismo o la planificación perfecta de la ortodoxia soviética. Para esto, cfr. Hinkelammert, Sacrificios humanos, 182.

6 De alguna manera, esta tesis está también de fondo en la obra de GAUCHET, M., La religión en la democracia, Madrid 2003, 24, cuando, hablando de la evolución de las democracias contemporáneas, afirma: «Eso quiere decir que la alteridad arrebatada a la trascendencia normativa resurge invisible, 
reino de Dios es el punto elástico de toda cultura progresiva y el comienzo de la historia moderna ${ }^{7}$. En efecto, la historia sigue teniendo una meta pero se ha producido una confusión de planos entre el cielo y la tierra:

Hinkelammert nos recuerda a Crisóstomo, uno de los padres de la iglesia, que decía en el siglo Iv:

«¡Hay que considerar, qué honor nos hizo Dios al darnos esta tarea! Yo, él dice, he creado el cielo y la tierra; también a ti te doy poder creador: ¡haz de la tierra un cielo! ¡Tú lo puedes!»

Se trata del problema del reino de Dios como el núcleo de lo terrenal. Lo es realmente y por eso este problema está presente en toda la modernidad a pesar de toda su secularización. Hasta se puede decir que todo el pensamiento de la modernidad da vuelta alrededor de este problema. La razón está en el hecho de que la sociedad con la modernidad es considerada un objeto de una transformación ${ }^{8}$.

El proceso emancipatorio que tiene lugar con el despertar moderno supone la emergencia de un sujeto que reivindica su potencial y su fuerza a la hora de acometer la transformación del mundo más allá de las brumosas apariencias de la religión. Ahora, lejos de tutelas religiosas, cielo y tierra se contradicen y quien pretenda afirmar la tierra tiene la obligación de abandonar el cielo9. De ahí que, también para Hinkelammert, la figura de Prometeo sea una perfecta metáfora del nuevo tiempo inaugurado:

Este mito de Prometeo proporciona los elementos para la imaginación prometeica a partir del Renacimiento. Todos los mitos construidos desde el del Prometeo griego tienen un rasgo común, que los distingue a todos del mito griego: en ellos Prometeo es visto como un hombre rebelde que se levanta frente a los dioses, deja de ser un dios y se transforma en hombre. El mito griego sirve más bien como una cantera para la reconstrucción mítica de una rebeldía y emancipación humanas, la cual es realizada por la sociedad moderna a partir del Renacimiento ${ }^{10}$.

Este hombre engrandecido, renegando del cielo, pretende, empero, descubrir el núcleo celeste de lo terrenal para poder orientar su acción desde él como punto de

innombrable para los actores pero indudablemente eficaz, en el interior del mecanismo político. Lo que se daba bajo una forma explícitamente religiosa se reencuentra bajo una forma operativa en el corazón del vínculo colectivo. En su dimensión más profunda, la retirada de la religión es la transmutación del antiguo elemento religioso en algo distinto de la religión. Por eso rechazo las categorías de laicización y secularización, porque no dan cuenta del sentido último del proceso. [...] Pero lo que está en juego es otra cosa y mucho más: una recomposición del conjunto del mundo humano por reabsorción, reforma y reelaboración de aquello que, durante milenios, tuvo el rostro de la alteridad religiosa».

7 Schlegel, F., Athenäums-Fragmente, no 222.

8 Hinkelammert, El sujeto y la ley. El retorno del sujeto reprimido, Heredia 2005, 503. También cfr. ID., «Plenitud y escasez: quien no quiere el cielo en la tierra, produce el infierno»: Polis, revista académica de la Universidad Bolivariana, vol. 3, nº (2004) 1-10.

9 A este respecto, Hinkelammert cita un poema de Heinrich Heine, donde se puede leer: «Ya en la tierra queremos construir el reino de los cielos [...] El cielo lo abandonamos para los ángeles y los gorriones», en El sujeto, 504. El cielo acaba estorbando y sólo hay lugar para esta tierra.

10 Hinkelammert, «Prometeo, el discernimiento de los dioses y la ética del sujeto: Reflexiones sobre un mito fundante de la modernidad»: Polis, revista académica de la Universidad Bolivariana, vol. $5, \mathrm{n}^{\circ} 13$ (2006) 2. También cfr. ID., Hacia una crítica de la razón mítica. El laberinto de la modernidad, San José 2007, 17-66. De esta manera, entendemos muy bien cómo para nuestro autor, inscrito en la corriente de la Teología de la Liberación, el problema fundamental no se encuentra en el binomio ateísmo-teísmo, sino más bien idolatría-fe. Por ello, junto a Marx, reivindica la necesidad de un discernimiento de los dioses, es decir, la distinción entre dioses de vida y dioses de muerte. Siempre, por tanto, y también en la racionalidad utópica moderna, hay dioses. 
partida $^{11}$. Este descubrimiento da lugar al pensamiento ideológico que, de una manera significativa, podría ser referido a la filosofía hegeliana y a su ecuación de ideal y real ${ }^{12}$.

Para Hinkelammert, la ideología tiene el nombre de utopía y su cometido es el de encontrar esa escalera que posibilita transitar de la tierra al cielo. Somos conscientes de la ambigüedad de términos como «ideología» y «utopía». Así, la palabra ideología tiene dos significados diversos, puede que dos caras de una misma moneda. En efecto, la ideología se presenta como sinónimo de cosmovisión o conjunto articulado de ideas; pero también, sobre todo en un sentido marxista, la ideología hace referencia a un discurso encubridor que legitima situaciones de injusticia. Del mismo modo, el término utopía puede ser interpretado, en un sentido negativo, como sinónimo de quimera; y en sentido positivo, como un modo de ser justo tanto del individuo como de la sociedad ${ }^{13}$. No obstante, pensamos que, con la ilustración, se produce un matrimonio indisoluble entre ambos términos que hace difícil el divorcio. En este sentido, como afirma J. A. Pérez Tapias:

En la Ilustración, la visión utópica queda, pues, cimentada por una filosofía de la historia que quiere dar cuenta racionalmente de su sentido, poniendo como su meta última el logro intrahistórico de aquella plenitud evocada por el simbolismo escatológico como consumación final de una «historia de salvación». Es lo que el pensamiento ilustrado pasa a concebir bajo el modelo de una «sociedad racional», la cual, puesta como meta intrahistórica desplazada a un futuro distante, pero hacia el cual se avanza, otorga renovada vigencia a la imagen mesiánica del final de la historia, reformulada ahora en términos de emancipación del hombre [...] Tal es ya la concepción utópica que fragua en el pensamiento dialéctico, con el que Hegel reforzará la idea de progreso, restándole ingenuidad al conjugarla con lo negativo de la historia ${ }^{14}$.

Así, aunque en la obra de Hinkelammert no encontramos una reflexión de modo explícito sobre la filosofía de Hegel y su vinculación al pensamiento ideológico, sin embargo, el fondo de la reflexión es una apelación permanente a dicha matriz. Quizás, la razón de esto pueda entenderse porque hablamos de planos de realidad distintos, el filosófico y el sociológico, y la vocación económica de nuestro autor haya dirigido más su atención al análisis de distintas teorías sociales. En palabras del filósofo alemán:

La necesidad de una crítica de la razón utópica en la actualidad no necesita mucha justificación. Desde todos los pensamientos sociales del siglo xix y ya de siglos anteriores nos viene la tradición de una especie de ingenuidad utópica, que cubre como un velo la percepción de la realidad social. Donde miramos, aparecen teorías sociales que buscan las raíces empíricas de los más grandes sueños humanos para descubrir posteriormente alguna manera de realizarlos a partir del tratamiento adecuado de esta realidad. Esta ingenuidad utópica está presente tanto en el pensamiento burgués - que atribuye a la realidad del mercado burgués la tendencia al equilibrio e identidad de intereses que originan en alguna mano invisible - como en el pensamiento socialista que atribuye a una reorganización socialista de la sociedad una perspectiva igualmente

11 El núcleo celeste de lo terrenal, en el caso del liberalismo (la mano invisible), o el núcleo terrenal de lo celeste, en el caso de Marx (la religión como mecanismo encubridor). Sin embargo, la idea de una confusión de planos, como veremos a continuación, está operante en ambos. Para ello, cfr. HiNKELAMMERT, El sujeto, 504.

12 «Was vernünftig ist, das ist wirklich; und was wirklich ist, das ist vernünftig», en HegEL, Grundlinien der Philosophie des Rechts, Werke 7, Frankfurt am Main 1970, 24.

13 Cfr. Pérez Tapias, Filosofía y crítica de la cultura, Madrid 1995, 68 y 97.

14 Ibid., 100. 
total de libertad del hombre concreto - De la tierra al cielo parece existir una escalera y el problema es encontrarla ${ }^{15}$.

A juicio de nuestro autor, el mecanismo por el cual la racionalidad utópica ha encontrado esta escalera ha sido mediante una secularización de los mundos trascendentes pertenecientes a las religiones, especialmente al cristianismo. Estos mundos trascendentes, donde se habla de una reconciliación plena del hombre con Dios, consigo mismo, con los otros y con la naturaleza, son secularizados y reemplazados por mundos trascendentales, donde se ha producido una idealización por abstracción de universos acabados que se proyectan al futuro como mecanismos de funcionamiento perfecto. Así pues, frente a la confrontación con una realidad que no satisface, se establece el mejor mundo posible depurando aquellos rasgos propios de la finitud, imperfección y contingencia humana y proyectándolo hacia el futuro como una societas perfecta más allá de este mundo. El objetivo de este proceso de abstracción es establecer un horizonte de sentido que movilice y oriente una praxis de transformación de la realidad. Afirma nuestro autor:

Se trata de un concepto trascendental, no de un concepto trascendente. La plausibilidad perfecta no es el cielo, pero cuando una sociedad expresa el cielo a partir de su nomos, lo expresa infaliblemente como un concepto idéntico a este concepto trascendental de la plausibilidad perfecta [...] El concepto de plausibilidad perfecta, es otra vez un concepto no-empírico y secularizado, y el cielo es un concepto trascendente y religioso igualmente no empírico. En cuanto conceptos son idénticos, sólo que aparecen en el hombre por caminos distintos; como concepto trascendental por una reflexión a partir de la realidad empírica mediatizada por un progreso infinito, y como concepto trascendente por un camino más bien mítico ${ }^{16}$.

Ahora bien, el problema surge cuando la racionalidad utópica olvida el carácter escatológico de la utopías; o de otro modo, el olvido del carácter trascendental del universo utópico va a ser el plano inclinado que introyecta la violencia en el devenir moderno: «A través de esta dialéctica maldita los conceptos trascendentales son transformados en valores absolutos, en nombre de los cuales todo es legítimo » ${ }^{17}$. Por tanto, se produce una confusión entre lo trascendente y lo trascendental, entre lo posible y lo imposible, entre una totalidad ausente, propia del universo escatológico religioso, y una totalidad presente, apropiación inconsciente de lo ideológico:

La utopía describe fines, que no son posibles de realizar, aun en el caso de que toda la humanidad unánimemente se decidiera por realizarla. La utopía remite al imposible, lo que trasciende a cada acción humana, a fines, que traspasan cada realidad humana como realidad quebrada y contingente, y por eso se encuentra más allá de la conditio humana. Hace parte de la sabiduría política, diferenciar a tiempo tales fines en su imposibilidad trascendental, porque ninguna derivación teórica puede comprobar su imposibilidad. En este proceso de diferenciación se forma el realismo político ${ }^{18}$.

La incapacidad de la razón utópica para diferenciar, como nos dice Hinkelammert, llevará a un pensamiento totalitario que fuerza a la realidad a entrar en sus dictados. La clave de comprensión de esta tendencia al totalitarismo radica en la cientificidad en la que parece querer basarse todo pensamiento ideológico y que hace de las utopías

15 Hinkelammert, Crítica de la razón utópica, Bilbao 2002, 9.

16 Ibid., 126.

17 Ibid., 206.

18 Ibíd., 384. 
mecanismos de funcionamiento perfecto ${ }^{19}$. Al final, el olvido de que la meta proyectada era un mundo idealizado alcanzable sólo como futuro meta-histórico, lleva al convencimiento de que lo utópico es lo real e incluso la única alternativa real ${ }^{20}$.

En efecto, cuando K. Marx realiza su crítica al capitalismo burgués emergente no lo hace sobre bases éticas sólidas, sino sobre un cálculo de posibilidad. Marx no afirma que el capitalismo sea bueno o malo, sino simplemente irreal porque, técnica y científicamente, son inviables unas relaciones mercantiles que conforman una sociedad caminando hacia su propia autodestrucción. Sin embargo, Marx sigue preso de la ilusión trascendental de un orden que se pueda establecer a priori como única alternativa posible al capitalismo, es decir, la sociedad socialista ${ }^{21}$. Del mismo modo, M. Weber, en sus análisis del socialismo, atendiendo no a juicios de valor, sino a juicios de hecho, argumenta que dicho socialismo es imposible porque la abolición de las relaciones mercantiles y del cálculo del dinero hacen imposible asegurar la vida real y concreta de los hombres. Así, la única alternativa posible es el capitalismo ${ }^{22}$. De ahí que se deba sospechar cómo el dualismo maniqueo al que nos confronta Marx y Weber no se funda en la realidad, sino en posicionamientos teoréticos:

Por ambos lados, las utopías [...] forman el contrapeso a la realidad precaria y amenazada; la realidad precaria está confrontada con la idea de una realidad idealizada. Pero la idea de una realidad lograda aparece como la realidad verdadera, como realismo político. El proceso técnico es interpretado como vehículo, que, aproximándose asintóticamente a la realización de la idea de una realidad lograda, es garante del supuesto realismo. Marx, los soviéticos, Weber y Hayek — todos— se consideran como los realistas verdaderos, que se hallan más allá de la utopía ${ }^{23}$.

Así se hace claro cómo las distintas utopías, reivindicando ser una explicitación palmaria de la realidad, han buscado un suelo firme en las ciencias empíricas. De esta manera, la utopía se considera praxis realista «más allá» de toda utopía y acaba destruyendo su propio mundo ${ }^{24}$. Lo usual es que la ciencia moderna describa la relación entre la realidad, algunas veces visiblemente inalterada en orden a la utopía, y el ideal, apriorísticamente propuesto, como una aproximación asintótica infinita ${ }^{25}$. Esto explicaría cómo el pensamiento utópico siempre desplaza sus propias culpabilidades a otros espacios o agentes. Es decir, la utopía parte del convencimiento de que no puede haber error en ella porque su realidad queda científicamente justificada con un conjunto de

19 En Hinkelammert, El nihilismo al desnudo. Los tiempos de la globalización, Santiago de Chile 2001, 36, se afirma: «la relación simétrica entre las ideologías staliniana y neoliberal es realmente sorprendente». Así hace notar nuestro autor que, estos mecanismos de funcionamiento perfecto, son propios tanto de utopías burguesas como revolucionarias. En relación a la cientificidad de los universos utópicos, hablando del capitalismo, Hinkelammert afirma en El huracán de la globalización, San José 1999, 243: «la política de eliminación de las distorsiones se presenta ahora como simple aplicación de una técnica».

20 Cfr. Hinkelammert, El nihilismo, 29-32.

21 Cfr. Hinkelammert, Determinismo, caos, sujeto. El mapa del emperador, San José 1996, 252-259.

22 Cfr. Hinkelammert, Crítica de la razón utópica, 367-390.

23 Ibid., 379.

24 Esta alianza entre utopía y ciencia es la clave de comprensión del proceso de objetivación o de reducción positivista del mundo en la crítica que la Escuela de Frankfurt hace a la razón instrumental. Para una valoración amplia de sus consecuencias cfr. V. VitıELlo, «Heidegger y el nihilismo»: Er, Revista de filosofía 29 (III/2000) 9-27.

25 Cfr. Hinkelammert, Sobre la concepción de sociedades perfectas en la metodología de las ciencias económicas, San José 2000, 5; ID., El nihilismo, 44-52 y D. SÁnchez RuBIo, «Sobre Crítica de la razón utópica de Franz Hinkelammert»: Araucaria. Revista Iberoamericana de Filosofía, Política y Humanidades, vol. 4, $\mathrm{n}^{\circ} 7$ (2002) $2 \mathrm{~s}$. 
leyes matemáticas ajenas a fallo. El mecanismo del chivo expiatorio es así algo presente en todos los movimientos de cuño ideológico:

En cambio, la modernidad occidental siempre persigue algunos «culpables», en los cuales antes ha proyectado sus propios problemas. Ella misma, se ve siempre inocente por las catástrofes producidas por ella. Para ella, otros son responsables, los cuales, naturalmente, luego tienen que ser perseguidos. Para Solschenyzin, "Asia», que se entrometió furtivamente en la moderna Rusia, tiene la culpa del estalinismo. Para Popper, el atavismo de una añoranza de la vuelta a la tribu, tiene la culpa de las catástrofes de la modernidad ${ }^{26}$.

\section{LA POSTMODERNIDAD O LA ANTI-UTOPÍA COMO JUSTIFICACIÓN DEL STATU QUO}

El concreto devenir del siglo xx ha dejado sobre el escenario de la historia tan sólo a la economía de mercado. Más aún, la presente crisis económica ha puesto en solfa la sostenibilidad del estado del bienestar y la izquierda sufre una profunda crisis de identidad. Así, la ideología liberal ha celebrado, por tanto, la caída de las distintas utopías, especialmente aquellas de cuño socialista, y se presenta a sí misma como la única alternativa posible ${ }^{27}$ :

Se trata de esta economía de mercado total, que desde alrededor de 20 años es ofrecida como alternativa para el Estado social burgués intervencionista de las décadas de los 50 y 60 y para los Estados o movimientos socialistas. Se ha impuesto hoy en muchos países del Tercer Mundo y en los EE.UU y siempre más es empujado en Europa Occidental. La misma palabra de mercado total fue acuñada por Henri Lepage, uno de los representantes más destacados del neoliberalismo en Francia. En nombre de este mercado total se sostiene hoy que no existe ninguna alternativa ${ }^{28}$.

En este sentido, Hinkelammert nos recuerda el libro de Kolakowski El hombre sin alternativa donde, ya en el año 1959, se habla de la sociedad staliniana como de una sociedad que se legitima a sí misma en el hecho de que no existe otra posible. De esta manera, el hombre se veía condenado a una sólo alternativa. Ahora es la economía de mercado la que, tras la caída del muro de Berlín, se presenta a sí misma como aquella que tiene razón y, por tanto, sin alternativa para ella ${ }^{29}$. Nos encontramos así ante un chantaje con una sola alternativa ${ }^{30}$.

Pero, ¿dónde se encuentra la raíz última de la legitimidad que el neoliberalismo esgrime para ofertarse como única alternativa? En el hecho de que el mercado total no se percibe a sí mismo como utópico, sino todo lo contrario. Es decir, el carácter no-utópico que parece esgrimir la economía de mercado es el suelo firme de su propia legitimidad. En este sentido, es importante hacer notar cómo el neoliberalismo ha encontrado una fiel alianza en las tesis pretendidamente científicas del anti-utópico K. Popper. En

26 Hinkelammert, Crítica de la razón utópica, 387 (n. 16).

27 Para esta parte, cfr. Hinkelammert, Sacrificios humanos, 161-173.

28 Hinkelammert, El nihilismo, 28.

29 «Como, aparentemente, ya no hay espacios de soluciones alternativas, la globalización y el sometimiento a ella es presentado como realismo [...] Las teorías económicas y sociales dominantes no analizan el proceso de globalización, sino que lo glorifican. El mercado total parece ser el fin de la historia y el conocimiento definitivo de lo que la humanidad tiene que hacer. Parece ser el espíritu absoluto», en HinKelammert, El huracán, 18.

30 Cfr. Hinkelammert, Crítica de la razón utópica, 259-262 e ID., El nihilismo, 29-32. 
referencia a su teoría de la falsabilidad, Popper establece un principio general empírico de imposibilidad que hace referencia al nunca jamás de un conocimiento perfecto y acabado de todo el conocimiento y, por ende, de todos los hechos de la relación humana interdependiente. De aquí se sigue la imposibilidad de una planificación del conjunto social; dado que su contrario descansaría en la posibilidad de un conocimiento ilimitado inconciliable con la esencia misma del hombre. Así, la crítica al pensamiento utópico aparece como demoledora porque el intento de realizar «lo imposible» va a producir como fruto más maduro la destrucción de la sociedad y el caos. O de otro modo, la utopía conduce a quien la abandera a la violencia y será legítimo reprimir al utopista aun por medio de la violencia. En resumen, «dada la imposibilidad de la planificación total, el intento de realizarla desemboca en una progresión infinita que es de mala infinitud en el sentido de que ni en un tiempo infinito llega a alcanzar su meta» ${ }^{31}$.

Se hace claro así la alianza entre el pensamiento neoliberal y las tesis científicas de un Popper que considera lo utópico como la pretensión de realizar lo imposible ${ }^{32}$. O de otro modo, «la hibris, que nos lleva a intentar realizar el cielo en la tierra, nos seduce a convertir nuestra buena tierra en un infierno - un infierno, que solamente seres humanos pueden realizar para otros seres humanos» ${ }^{33}$. En síntesis, podemos afirmar:

El mercado total en su representación del automatismo del mercado es como tal, utópico en el sentido de una societas perfecta y de una institución perfecta. Pero se trata de una utopía que no es percibida como tal, sino que es identificada con la realidad. Reconocerla es considerado como realismo o pragmatismo. El neoliberal, al pronunciar sus utopías, se siente realista. Acto seguido, se enfrenta este realismo aparente a todas las utopías, con el resultado de que todas las imaginaciones de libertad o solidaridad, que cuestionan el mercado, parecen ser utopías. Por lo tanto, la ideología del mercado total se hace pasar como anti-utópica ${ }^{34}$.

En efecto, los argumentos liberales pueden ser sintetizados en tres pasos. En primer lugar, los neoliberales reconocen la destrucción que se está produciendo de las fuentes de la producción de toda la riqueza mundial, aunque a penas la mencionan. En segundo lugar, y como tesis central, se contrapone a esta crisis, con consecuencias desastrosas como la exclusión de una gran parte de la población mundial y la destrucción acumulativa de la naturaleza, el axioma de la existencia de una mano invisible del mercado que produce una autorregulación de fuerzas conducentes a una armonía para el interés de todos. De aquí se ha de deducir una confesión de fe en el mercado y en dichos procesos de autorregulación. Tercero, si se está produciendo destrucción a gran escala es debido al hecho de la injerencia en los mecanismos internos de funcionamiento del mercado. $\mathrm{O}$ de otro modo, las fallas del mercado se han de resolver con más mercado, las fallas de tecnología con más tecnología, las fallas de guerra, con más armamentos, etc...

Así pues, es importante destacar cómo entre el liberalismo y el neoliberalismo, a juicio de Hinkelammert, se ha producido un profundo corte. El liberalismo clásico de Keynes no totalizaba el mercado y admitía que, junto a la mano invisible, era necesaria otra visible que ayudara a corregir ciertas inercias del mismo. Ahora, la política de los grandes centros financieros postula la necesidad de globalización de los mercados. La consecuencia de todo esto es manifiesta para nuestro autor:

31 Hinkelammert, Crítica de la razón utópica, 23. Es interesante el magnífico estudio que nuestro autor realiza en el capítulo I de la obra citada y que lleva por título: La metodología de Popper y sus análisis teóricos de la planificación, la competencia y el proceso de institucionalización.

32 Cfr. Popper, K., La miseria del historicismo, Madrid 1973, 94.

33 Frase de Popper tomada de Hinkelammert, El sujeto, 505.

34 Hinkelammert, El nihilismo, 118. 
Lo que resulta es, aceptando el concepto de totalitarismo de Hannah Arendt, una ideología totalitaria, que lleva a puras políticas de tabula rasa, que en el lenguaje neoliberal se llama "política de choque». Se guía por un principio, que Reagan usó frecuentemente en sus campañas electorales: «No hay problema con el Estado, el Estado es el problema». Hayek lo vincula inclusive con la mística de la "última batalla» ${ }^{35}$.

Pero lo verdaderamente interesante de esto es que el neoliberalismo no sólo reivindica su carácter no-utópico, sino que se muestra beligerantemente anti-utópico, es decir, quien pretende el cielo en la tierra lo que produce es el infierno; por esta razón hay que luchar contra todo tipo de utopía ${ }^{36}$. Lo que subyace a tal pretensión es una sacralización de las relaciones de producción que impone la fe en el evangelio del neoliberalismo económico, cuyas bienaventuranzas serían: la abundancia como satisfacción de todos los deseos, la promesa de un crecimiento sin fin, la unidad de todos los hombres en torno al mercado y la confianza en que las fuerzas salvíficas del mercado van a superar la actual destrucción de la naturaleza y del ser humano. De este modo, cuando no está permitido revelarse contra el nuevo dios, lo que se produce, paradójicamente, es una justificación del statu quo. En efecto, la paradoja radica en el hecho de que siendo el neoliberalismo claramente utópico, no permite la más mínima crítica al presente. O de otro modo, la utopía neoliberal, instalada en el poder, promete un mundo mejor pero afirmando ciegamente el mundo que ellos mismos han instaurado. Al final, el pensamiento anti-utópico neoliberal es una no verdadera superación de la totalidad ciega ilustrada, sino permanecer atados a la misma lógica, puede que con el signo menos delante del paréntesis:

La utopía presenta un problema de la civilización occidental. Con la modernidad, la razón misma llegó a ser utópica. Toda razón moderna gira alrededor del problema de lo posible y de lo imposible. Por eso, el problema de la utopía se encuentra en todos los pensamientos que aparecen en la modernidad, incluso en la llamada postmodernidad, la que, por otra parte, hay que interpretar como una variación (Spielart) de la modernidad y nada más ${ }^{37}$.

La postmodernidad, desde este punto de vista, sigue siendo profundamente moderna y no ha conseguido superar aquello mismo que pretendía criticar ${ }^{38}$ : "Pero siempre hay que volver a entrar al laberinto de la modernidad porque no hay otro camino. No hay postmodernidad ${ }^{39}$. Es interesante constatar cómo la anti-utopía neoliberal sigue siendo tan totalitaria y violenta como los distintos paraísos ideológicos del pasado siglo xx. Ahora bien, si antes nos encontrábamos ante la totalización de un exceso de sentido, lo postmoderno se perfila como totalización del sinsentido. En efecto, una sociedad que sostiene que fuera de ella no hay alternativa, sólo puede tener como criterio movilizador la eficacia formal, es decir, el criterio ya no es lo ético, sino aquello que es posible concebir en la realidad. El resultado es evidente:

De esta manera, se contraponen el criterio de eficiencia formal por un lado, y todos los derechos humanos por el otro. Estos mismos derechos son destruidos cuando ya no son respetados en cuanto tales, sino que reciben su validez en el grado en el cual

35 Ibíd., 117. Cfr. también para este tema Y. AzofeIfa SÁnchez, «La crítica de Franz J. Hinkelammert a Friefrich A. von Hayek. El marco categorial del pensamiento neoliberal»: Revista de Ciencias Sociales (II/2003) 133-146.

36 Cfr. Hinkelammert, El nihilismo, 118s.

37 Hinkelammert, Crítica de la razón utópica, 387. La misma idea en ID., Sacrificios humanos, 178: «Eso es el fin del Occidente, y la postmodernidad no es más que esta misma modernidad occidental in extremis".

38 Cfr. Hinkelammert, La fe de Abraham y el Edipo occidental, San José 1989, 81-101.

39 Hinkelammert, Hacia una crítica de la razón mítica, 12. 
aportan a la eficiencia o no. Si el criterio de la eficiencia formal domina sobre todos los valores, la relación con los valores se torna puramente nihilista. Valores, que valen para el caso en que coinciden con las exigencias de la eficiencia y dejan de tener valor en cuanto no coinciden, no tienen ningún valor ${ }^{40}$.

Además, a juicio de nuestro autor, tendría aquí cabida, de forma absolutamente actual, la crítica que K. Marx dirige al carácter sagrado del capitalismo en El Capital hablando del fetichismo de la mercancía ${ }^{41}$. Marx detecta que el capitalismo es profundamente religioso y monoteísta porque, aun bajo la apariencia de secularización, elabora una re-sacralización de la realidad. Este carácter sagrado se fundamenta en un dogma que no admite la herejía: la tiranía del beneficio. De esta manera, todo lo sólido se desvanece en el aire con un disolvente que se convierte en la mayor máquina nihilista del mundo: el capital. Al final, el único valor se expresa en precio y la clase emergente, la burguesía, es capaz de venderlo todo. El análisis de Marx es muy agudo y evidencia el sustrato ontológico fuerte que sostiene al sistema capitalista y que no admite interferencia o bloqueo alguno ${ }^{42}$.

Este monoteísmo productor de nihilismo llega a tal extremo que Hayek excluye incluso la crítica al mercado en nombre de sus resultados. Más aún, aunque el mercado destruyera la propia condición humana, la crítica quedaría excluida. «De esta manera, la ideología del mercado se transforma en la ideología del heroísmo del suicidio colectivo » ${ }^{43}$. El referente, por tanto, del nuevo tiempo es, sin duda, la figura de Nietzsche:

Marx creía que la toma de conciencia con referencia a la tendencia a la destrucción llevaría inevitablemente a la conversión y a la búsqueda y aceptación de las alternativas necesarias. Pero evidentemente eso no es el caso. La humanidad puede aceptar y celebrar su suicidio colectivo. Hay hoy una tendencia clara de este tipo. Por eso Nietzsche vuelve a ser de nuevo nuestro clásico. En Marx se puede leer lo que hemos perdido. En Nietzsche, adónde vamos. A la utopía, de la cual se sostiene que, porque quiere el cielo en la tierra, produce el infierno, nuestra sociedad sin alternativas opone la mística del suicidio colectivo. A la posibilidad del infierno en la tierra opone su seguridad. Para no ser sorprendido con los ojos cerrados por la utopía, se marcha al infierno con los ojos abiertos $^{44}$.

Por último, la justificación de esta tendencia al nihilismo como suicidio colectivo se hace especialmente manifiesta cuando se analiza el paso del capitalismo utópico al capitalismo "cínico», en palabras de nuestro autor ${ }^{45}$. Para ello, puede ser significativa la cita de dos textos tipo que ilustran ambas posturas y que, por tanto, dibujan con trazo fino dicho corrimiento. En referencia al capitalismo utópico:

Una existencia humanamente digna presupone la superación de las emergencias económicas y sociales, presupone la disponibilidad de los bienes necesarios para la vida y de lugares de trabajo seguros. El sistema de mercado asegura todo eso gracias a su alta eficiencia. El motor de la economía de mercado es la competencia. Pero su función no se limita a asegurar la dinámica económica. «Domestica la propiedad privada» y es el «instrumento más genial para quitar el poder», como dice Franz Bohm. El sistema

40 Hinkelammert, El nihilismo, 33.

41 Cfr. Marx, K., El Capital, Madrid 1968, 15s.

42 Cfr. Pérez, J.A. Tapias, El pensamiento, en Hinkelammert, Solidaridad, 16.

43 Hinkelammert, El nihilismo, 34.

44 Ibid., 43. También cfr. Hinkelammert, Solidaridad, 31-34.

45 Para lo que sigue cfr. Hinkelammert, El nihilismo, 67-90 e ID., Solidaridad, 41-46. 
de mercado se basa en el interés propio. Pero la astucia del sistema logra que el interés propio, que entra en competencia, opere a favor del bien de la comunidad ${ }^{46}$.

En referencia al capitalismo cínico extractamos el siguiente texto tipo:

El nuevo imperativo económico está claro: los suministradores de ultramar en los países en desarrollo o alcanzan con sus tecnologías los estándares de la velocidad mundial, o se los va a cortar brutalmente de sus mercados - los muertos caídos del efecto de aceleración- [...] Esta es la economía rápida de mañana. Ella es la nueva máquina del bienestar acelerativa, dinámica, que es la fuente del avance económico. Como tal es también la fuente de un gran poder. Estar desacoplado de ella significa estar desacoplado del futuro. Pero eso es el destino que enfrentan muchos de los países LDC o países menos desarrollados [...] Como el sistema mundial de la producción de riqueza está arrancando, los países que quieren vender tienen que operar a la misma velocidad que los países compradores. Eso significa que las economías lentas o aceleran su respuestas neutrales o pierden sus contratos e inversiones, o caen completamente fuera de la carrera $[. .$.$] Un "gran muro» separa a los rápidos de los lentos, y este muro está creciendo$ cada día que pasa ${ }^{47}$.

A partir de estos textos, prototípicos de sendas posturas, Hinkelammert cataloga con tres adjetivos a cada forma de capitalismo. Mientras que el capitalismo utópico puede ser adjetivado como falso, ideológico e hipócrita, el capitalismo cínico se considera cierto, sacralizador y honesto. En efecto, el texto primero es falso porque el interés propio combinado con la competencia no produce el bien común; ideológico porque sacraliza las relaciones sociales de producción recurriendo incluso a una confesión de fe en un ente abstracto que reorganiza el juego en beneficio de todos; hipócrita porque su autor sabe que lo que dice es falso. El segundo texto es cierto porque deja de lado cualquier referencia al bien común e imputa al mercado la tendencia a la exclusión; sacralizador porque sigue canonizando las relaciones sociales de producción pero ya no en orden a un bien común ${ }^{48}$, sino mediante la aceptación de la aceleración misma como un hecho; honesto porque Toffler dice verdad.

Ahora bien, la honestidad del segundo texto es tan hiriente que podemos entender su adjetivación como "cínico». La totalización del mercado como producto interesado del proceso de globalización nos lleva a un actual sistema que se legitima a sí mismo sin referencia a ningún potencial de razón y que, por tanto, nos deja desarmados para un posible debate crítico. Este capitalismo se remite a los hechos, sacraliza la falta de alternativas y celebra la "destrucción creadora» ajena a cualquier sentimiento trágico. «Pero lo que resulta de esta posición cínica es un nihilismo» ${ }^{49}$. En palabras de Hinkelammert:

El capitalismo cínico acepta los juicios de hecho subyacentes a esta crítica. Los transforma en afirmación del capitalismo por la simple tesis de que no hay alternativa. Como no hay alternativa, estos juicios de hecho se transforman en deber. ¿El mercado es un fetichismo? Se contesta: sí, pero lo es ¿y qué? Si lo es, también tiene que serlo, porque alternativa no hay. Eso se hace con los otros juicios de hecho subyacentes a la

46 LambsdorfF, O.G., «Gezähmtes Eigentum. Für den Vorsitzenden der Freien Demokraten ist die soziale Markwirtschaft die moralischste aller Wirtschaftsformen», en Wirtschafts Woche 45 (1-11-91), 104s. Tomado de El nihilismo, 69. Este capitalismo utópico tiene también un referente en M. Friedman. Para ello, cfr. Hinkelammert, Crítica de la razón utópica, 164.

47 Toffler, A, Powershift, Knowledge, Wealth and Violence and the Edge of the 21st Century, New York 1991, 389-405. Tomado de El nihilismo, 71s.

48 Cfr. Hinkelammert, El huracán, 239-249.

49 Hinkelammert, Solidaridad, 45. 
crítica clásica del capitalismo. ¿El capitalismo es un sistema de explotación? ¿Y qué? ¿El capitalismo destruye al ser humano y a la naturaleza? ¿Y qué? ¿Por qué no, si el mundo es así y no hay alternativa? ${ }^{50}$

Al final, el universo totalitario nacido del deseo de emancipación del hombre ilustrado nos lleva paradójicamente a otro horizonte no menos totalitario, pero de signo contrario. El desarrollo de la parábola moderna, con el crecimiento agigantado del actual capitalismo neoliberal, nos deja paralizados para la lucha y cierne sobre nosotros los peligros de un sistema completamente tautologizado que legitima, sin más, el suicidio colectivo como horizonte. Por esta razón, y a juicio de nuestro autor, hoy más que nunca se hace urgente la construcción de un nuevo pensamiento que, fundado en el bien común, no vea al hombre como un ser para la muerte, sino como un ser para la vida ${ }^{51}$.

\section{Lo ÚtIL FRENTE AL CÁLCULO DE UTILIDAD O YO SOY EL OTRO}

El pensamiento de F.J. Hinkelammert no se cierra en lo analítico, sino que tiene una proyección propositiva que es necesario mencionar. En este sentido, es central su concepción antropológica que bien podría ser tematizada como la de un ser infinito que sólo se realiza en la finitud. De esta manera, Hinkelammert realiza una encendida defensa del pensamiento utópico como parte de la condición humana misma, convencido de que quien no quiere el cielo en la tierra, produce el infierno:

No consideramos el carácter utópico de la razón moderna como una confusión, de la cual se tuviera que salvar la razón, sino como una dimensión en su interior, de la cual tenemos que tomar conciencia. Por consiguiente, la crítica de la razón utópica no se propone la tarea de abolir la utopía. Esa sería la utopía más peligrosa y más destructora de todas. El pensar en utopías hace parte de la conditio humana misma. Quien proclama el fin de las utopías, llega a un levantamiento ciego y por eso inhumano contra la conditio humana ${ }^{52}$.

Ahora bien, el filósofo alemán sí pretende conscientemente una corrección crítica a la concepción ideológica de la modernidad. En este sentido, su postura equivaldría a la reivindicación de lo que podríamos llamar «mitos desmitologizados», es decir, utopías trascendentales, pero no empíricas, con respecto al ideal regulativo ${ }^{53}$. O de otro modo, utopías proyectadas como condiciones de posibilidad que dirigen la praxis histórica, pero conscientes de la imposibilidad de realizar el ideal apriorístico propuesto. O también, utopías que no confunden lo trascendente con lo trascendental, la totalidad ausente con la totalidad presente, lo escatológico con lo histórico. Se trata, por tanto, de una concepción dialéctica que mantiene siempre la tensión en el límite de lo posible y de lo imposible, es decir, que desacralizan el sistema para historizarlo, mostrando su génesis y desarrollo y haciéndolo susceptible de posibles cambios:

Sin embargo, el realismo político, contrapuesto a la «Realpolitik», jamás puede afirmar poder realizar la utopía ella misma. Para ello, la utopía es una fuente de ideas de la buena vida, un punto de referencia para el juicio, una reflexión de sentido. Para

\footnotetext{
50 Hinkelammert, El nihilismo, 77.

51 Cfr. Fernández Nadal, "El pensamiento de Franz Hinkelammert desde la perspectiva de una filosofía latinoamericana»: Utopía y Praxis Latinoamericana, vol 6, nº 12 (2001) 57.

52 Hinkelammert, Crítica de la razón utópica, 388.

53 Cfr. Pérez TAPIAs, J.A., «Mito, ideología y utopía. Posibilidad y necesidad de una utopía no mitificada»: Gazeta de Antropología, nº 6 (1988).
} 
cumplir con eso, la utopía jamás debe llegar a ser un fin por realizar de manera asintótica y por tanto calculable [...] la utopía sigue siendo una idea regulativa ${ }^{54}$.

Así pues, ¿de dónde brota la necesidad de mantener un pensamiento utópico críticamente vigilado? Del hecho de que sólo pensando lo imposible podemos conocer aquello que es posible, porque sólo proyectándonos más allá de la condición humana podemos saber el qué de la misma. O de otra manera, «la utopía abre la realidad y desde lo imposible muestra sus posibilidades ${ }^{55}$. En este sentido, nuestro autor se muestra categórico:

No se trata de algo obvio. Todavía Max Weber rechaza esas propuestas: «Es exacto - si se lo entiende correctamente- que la política exitosa es siempre el arte de lo posible. Pero, no es menos cierto que muy a menudo lo posible sólo se obtuvo porque se procuró lo imposible que está más allá de él». Inclusive Max Weber todavía tiene conciencia del hecho de que restringirse a metas pretendidamente realistas no es para nada realista. Un realismo tiene que incluir la conciencia de que se trata muy a menudo de hacer posible lo imposible. Quien no apunta hacia lo imposible jamás va a descubrir lo que es posible. Ernst Bloch expresa: «....apuntar más allá de la meta para dar en el blanco». Lo utópico no es lo irrealista, sino condición de la propia acción realista ${ }^{56}$.

Desde estas claves, reivindicando la resistencia del sujeto vivo frente al mercado global, Hinkelammert ensaya una ética del bien común como exigencia de transformación del sistema. Dicha transformación tiene una orientación socialista y demócrata, pero la misma no es una afirmación de una sociedad concreta y determinada, a la manera de una societas perfecta. Afirmarlo así sería volver a caer en las redes de la razón utópica moderna.

Situados aquí, Hinkelammert hace una reflexión sobre el cálculo de utilidad, subyacente al sistema neoliberal, para denunciar, paradójicamente, su poca utilidad: el máximo beneficio, con el menor coste, y en el más breve tiempo. En efecto, lo malo es útil y lo bueno es inútil al sistema, es decir, el neoliberalismo critica la ética de S. Martín ${ }^{57}$ y nos persuade de que los vicios privados, fundados en el egoísmo, hacen la prosperidad pública $^{58}$. De esta manera, y como ya hemos apuntado suficientemente, el actual sistema de cosas nos lleva al abismo de la exclusión de una inmensa mayoría de la población mundial y a una destrucción irreparable de la naturaleza. La paradoja de las utilidades desvela que el cálculo de utilidad no es útil porque nos lleva a un suicidio colectivo. $\mathrm{O}$ de otra manera, el asesinato es suicidio:

La autorrealización solamente es posible en el otro y junto a él. Pero eso presupone una utilidad que está en conflicto con el cálculo de utilidad. Utilidad no es calculable porque rompe el cálculo de utilidad totalizado. Se trata de la utilidad que está en la afirmación del otro - en última instancia el otro es la humanidad y el cosmos- del cual soy parte al ser yo en el otro y el otro en mí. No se trata de efectuar algún sacrificio a favor del otro para que pueda vivir también. Que el otro viva es condición de posibilidad de mi vida. Al afirmar yo esta relación me auto-realizo. Implica excluir el asesinato

54 Hinkelammert, Crítica de la razón utópica, 383s. Interesante hacer notar la diferencia entre «realismo político» y «Realpolitik». Esta última es un producto encubridor de un neoliberalismo que se presenta como la única alternativa posible. Para ello, cfr. ID., Sacrificios humanos, 189.

55 Pérez Tapias, J. A., Filosofía, 103.

56 Hinkelammert, El sujeto, 506. También cfr. ID., Crítica de la razón utópica, 380ss.

57 Nuestro autor se refiere a S. Martín de Tours, santo del siglo Iv. Es popularmente conocido por haber partido la mitad de su capa de soldado romano para compartirla con un mendigo que sufría las inclemencias del frío. Días después, y según la leyenda, Cristo mismo se le habría aparecido vistiendo la capa que había entregado al mendigo.

${ }_{58}$ Cfr. Hinkelammert, Sacrificios humanos, 166-173. 
como medio de la auto-realización. Aparece un principio de la auto-realización que sigue de un postulado de la razón práctica que sostiene: asesinato es suicidio ${ }^{59}$.

La propuesta ética de nuestro autor, cercana e inspirada en el pensamiento judío del pasado siglo xx, especialmente en E. Levinas, y también en el cristianismo, hace una reivindicación decidida de la infinita dignidad de lo concreto, es decir, del hombre. Frente a los sistemas totalitarios de modernidad y postmodernidad, en medio de un neoliberalismo cínico y salvaje, Hinkelammert nos recuerda dos evidencias: el bien solitario que deja al mundo abandonado a su suerte es repugnante y, sobre todo, solo hay futuro verdadero cuando hay futuro para todos. Con sus propias palabras: «No habrá arca de Noé para algunos. O todos caben, o ninguno» ${ }^{60}$.

\section{CONCLUSIÓN}

Un acercamiento atento a la obra de F.J. Hinkelammert muestra una meditada reflexión acerca del desarrollo concreto de la historia de la humanidad, a la manera de una filosofía de la historia. En efecto, el devenir de nuestro mundo es el proceso dialéctico en el que, frente a todo poder instituido que oprime al hombre concreto, se levanta un sujeto que resiste e impulsa transformaciones históricas que dan lugar a nuevas configuraciones sociales más sensibles al reconocimiento de la infinita dignidad de la persona. Ahora bien, estas nuevas configuraciones sociales, pretendiendo favorecer el desarrollo humano, cristalizan en instituciones, que por una lógica inherente a las mismas acaban independizándose del hombre, se sacralizan y terminan por someter al sujeto que las había proyectado. Esta visión dialéctica da razón de las fuerzas sociales que continuamente están reconfigurando el concreto mundo en que vivimos.

De ahí la necesidad de escuchar el grito del sujeto reprimido, de modo que sea el ser humano el centro y el fin de toda actividad política, social y económica. Ante toda totalización, en nuestros días la del mercado, nos quedamos con una intuición profundamente sapiencial de nuestro autor: el asesinato es suicidio.

Facultad de Teología de Granada

José SERAFín BéJAR Bacas serabejar@gmail.com

[Artículo aprobado para publicación en diciembre de 2014].

59 Hinkelammert, Solidaridad, 50. Cfr. también para esta reflexión ID., El nihilismo, 151-184.

60 Hinkelammert, Sacrificios humanos, 191. 